УДК 628. 54

DOI

\title{
АКТИВАТОРИ ПРОЦЕСУ ПОГЛИНАННЯ ВУГЛЕКИСЛОГО ГАЗУ ХЛОРОФІЛСИНТЕЗУЮЧИМИ МІКРОВОДОРОСТЯМИ
}

\author{
Дячок В.В. д. т. н. професор, Мандрик С.Т. аспірант, Гуглич С.І. к. т. н. доцент,
} Національний університет «Львівська Політехніка»

\begin{abstract}
Анотація. Зміна загальнопланетарного клімату призводить до руйнівних наслідків для планети Земля $і$ робить иңю проблему однією з найважливіших у сфері охорони навколишнього середовища . Існує багато способів для вирішення иієї проблеми, одна із них зменшення концентрації $\mathrm{CO}_{2}$ із залученням біологічних методів очищення промислових газових викидів із використанням фотосинтетичних властивостей мікроводоростей. Найвагомішим джерелом вуглекислого газу $\left(\mathrm{CO}_{2}\right)$ є спалювання палива, твердого, рідкого чи газоподібного. А відповідно супутніми продуктами спалювання є діоксид сульфуру $\left(\mathrm{SO}_{2}\right)$, оксиди нітрогену $\left(\mathrm{N}_{x} \mathrm{O}_{y}\right)$, оксид фосфору $\left(\mathrm{P}_{2} \mathrm{O}_{5}\right)$ та інші.

Безумовно присутність ијих газів буде впливати на ефективність поглинання $\mathrm{CO}_{2}$ хлорофілсинтезуючими мікроводоростями типу Chlorella. Тому важливо дослідити вплив $\mathrm{N}_{x} \mathrm{O}_{y}, \mathrm{P}_{2} \mathrm{O}_{5}$ на ефективність поглинання вуглекислого газу хлорофілсинтезуючими мікроводоростями типу Chlorella. Раніше нами було доведено, щуо діоксид сульфуру виступає інгібітором процесу поглинання вуглекислого газу (фотосинтезу). Причому інгібіювання носить звортній характер, а від так є можливість керувати прочесами поглинання парникових газів за присутності $\mathrm{SO}_{2}$.

В даній роботі встановлено явище активування оксидами нітрогену та оксидом фосфору процесу поглинання вуглекислого газу. Встановлені допустимі значення концентрацій активаторів $\left(\mathrm{N}_{x} \mathrm{O}_{y}\right.$ mа $\left.\mathrm{P}_{2} \mathrm{O}_{5}\right)$ в процесі поглинання вуглекислого газу хлорофілсинтезуючими мікроводоростями. На основі рішення розробленої математичної моделі поглинання вуглекислого газу хлорофілсинтезуючими мікроводоростями та отриманих експериментальних результатів дослідження отриманоо графічні та аналітичні залежності поглинання вуглекислого газу хлорофілсинтезуючими мікроводоростями за умови присутності оксиду фосфору та оксидів нітрогену. Визначено значення оптимальної концентрачії оксидів нітрогену та оксиду фосфору як активаторів приросту мікровдоростей типу Chlorella.
\end{abstract}

Ключові слова: вуглекислий газ $\left(\mathrm{CO}_{2}\right)$, оксиди нітрогену $\left(\mathrm{N}_{\mathrm{x}} \mathrm{O}_{\mathrm{y}}\right)$, оксид фосфору $\left(\mathrm{P}_{2} \mathrm{O}_{5}\right)$, мікроводорості, активатори.

\section{ACTIVATORS OF THE PROCESS OF ABSORPTION CARBON DIOXIDE BY CHLOROPHYSYNTHESIZING MICROALGAE}

Vasil Dyachok, Doctor of Engineering Science, Professor; Solomiia Mandryk postgraduate; Serhii Huhlych, Ph.D. in Engineering Science, Associate Professor; Lviv Polytechnic National University, Lviv, Ukraine

\begin{abstract}
Changing the planet climate leads to devastating consequences for the planet Earth and makes this problem one of the most important in the field of environmental protection. There are many ways to solve this problem, one of which is the reduction of $\mathrm{CO}_{2}$ concentration with the use of biological methods for the purification of industrial gas emissions using the photosynthetic properties of microalgae.The main source of carbon dioxide $\left(\mathrm{CO}_{2}\right)$ is combustion of fuel, solid, liquid or gaseous.

Consequently, by-products of combustion are sulfur dioxide $\left(\mathrm{SO}_{2}\right)$, nitrogen dioxide (NxOy) phosphorus oxide $\left(\mathrm{P}_{2} \mathrm{O}_{5}\right)$ and other. Certainly, the presence of these gases will affect the absorption efficiency of $\mathrm{CO}_{2}$ chlorophyllsynthesizing microalgae of the Chlorella type. Therefore, it is important to study the effect of NxOy and $\mathrm{P}_{2} \mathrm{O}_{5}$ on the absorption efficiency of carbon dioxide chlorophyllsynthesizing microalgae of the Chlorella type. Previously, we defined that sulfur dioxide is an inhibitor of the process of absorption of carbon dioxide (photosynthesis). It needs to be say that inhibition is the reverse, and so it is possible to control the processes of absorption of greenhouse gases in the presence of $\mathrm{SO}_{2}$.

In this article, the phenomenon of activation by oxides of nitrogen and phosphorus in the process of absorption of carbon dioxide are established. The established values of activator concentrations (NxOy and $\left.\mathrm{P}_{2} \mathrm{O}_{5}\right)$ in the process of absorption of carbon dioxide by chlorophyllsynthesizing microalgae. Based on the decision of the mathematical model and the experimental results obtained, graphs of the dependence of the absorption of carbon dioxide on the chlorophyllsynthetic microalgae were constructed in the presence of phosphorous oxide and nitrogen
\end{abstract}


oxides. The values of optimal concentration of nitrogen oxides and phosphorus oxides as enhancers of growth of microalgae of the Chlorella type were determined.

Key words: carbon dioxide $\left(\mathrm{CO}_{2}\right)$, nitrogen dioxide $\left(\mathrm{NO}_{2}\right)$, phosphorus oxide $\left(\mathrm{P}_{2} \mathrm{O}_{5}\right)$, sulfur dioxide $\left(\mathrm{SO}_{2}\right)$, microalgae, activators.

Актуальність проблеми. Глобальне потепління, яке викликане збільшенням концентрації парникових газів в атмосфері, викликає серйозне занепокоєння і привертає все більшу увагу оскільки природні джерела викопного палива виснажуються. Ефективне зменшення викидів парникових газів $\epsilon$ важливою міжнародною проблемою в наукових, і екологічних спільнотах і навіть в міжнародній економіці та політиці. Вуглекислий газ $\left(\mathrm{CO}_{2}\right)$ є одним з основних парникових газів, що викидаються в атмосферу. Таким чином, зменшення викидів $\mathrm{CO}_{2}$ за допомогою біологічних методів $\epsilon$ важливим завданням екологічної спільноти сьогодення. [1]

Серед біологічних методів, фотосинтез мікроводоростей має ряд переваг, таких як вища швидкість фіксації $\mathrm{CO}_{2}$, ніж у наземних рослин, також необхідності в подальшій утилізації захопленого $\mathrm{CO}_{2}$ немає. Біологічна фіксація $\mathrm{CO}_{2}$ за допомогою мікроводоростей розглядається як потенційна тактика не тільки зменшити викиди $\mathrm{CO}_{2}$, але і отримати біомасу мікроводоростей з високим вмістом ліпідів (джерело регенеративної енергіï). Включення $\mathrm{CO}_{2}$ в компоненти запасу енергії в біомасі, такі як вуглеводи і ліпіди, заснована на фотосинтезі і фіксації $\mathrm{CO}_{2} €$ найбільш перспективним шляхом для вловлення вуглекислого газу з газових викидів. [2]

Хлорофілсинтезуючі мікроводорості мають ряд суттєвих переваг. Вони не потребують добрив, не потребують багато місця на відміну від наземних культур. Фактично вони створюють потужну конкуренцію традиційним культурам. До того ж, водорості швидко ростуть. Вони можуть рости будь-де, якщо отримують достатньо світла, води і вуглекислого газу, який поглинають. Водночас самі нейтралізують речовини, які забруднюють воду при їх культивуванні. Отож вирощування водоростей вважається екологічно чистим виробництвом. [3]

Основні чинники, що впливають на процес фотосинтезу мікроводоростями $є$ ступінь аерації вуглекислим газом, температура, освітленість, лужно-кислотний баланс, вплив активаторів реакції фотосинтезу і т. д. За рахунок дослідження цих факторів можна отримати більш глибоке розуміння біологічних процесів, що відбуваються у досліджуваному об'єкті. [4]

Мета роботи полягає у вивченні впливу оксидів, які можуть виступати в ролі активаторів процесу фотосинтезу при поглинанні вуглекислого газу хлорофілсинтезуючими мікроводоростями типу Chlorella.

\section{Теоретична частина.}

Всі процеси у живій природі протікають винятково ферментативним шляхом. Тому перетворення забруднюючих речовин всередині клітини мікрводорості відбувається завдяки дії ферментів. За даними сучасних досліджень активністю ферментів можна регульовати. Більшість ферментів можуть зв'язуватися з малими молекулами, які мають назву модифікатори (ефектори) і можуть змінювати ферментативну активність. До них належать: інгібітори- сполуки, які гальмують активність ферменту та активатори - сполуки, які збільшують ферментативну активність. Відповідно результат дії інгібіторів має назву інгібування, активаторів активація. [5].

Швидкість протікання біохімічних процесів залежить не тільки від природи і концентрації ферменту та субстрату, але й від присутності - інгібіторів і активаторів. В живій природі інгібіювання і активація ферментів і ферментних систем $\epsilon$ найважливішими засобами регулювання метаболізму і пристосування до умов навколишнього середовища [6].

Активація ферментативної активності найчастіше може відбуватися під дією кофакторів, субстратів або інших метаболітів. Кофактори можуть позитивно впливати на зв'язування субстрату з активним центром, каталітичне перетворення субстрату, іноді утворюють метало-субстратні комплекси, які більш ефективно підлягають дії ферменту. Молекули субстрату також можуть активувати фермент, але за рахунок інших механізмів. Відомо, що молекули субстрату стабілізують структуру ферменту та індукують необхідні конформаційні зміни в активному центрі. [7]

Активуючий вплив на швидкість ферментативної реакції надають речовини органічної і неорганічної природи. Активатори в свою чергу не можуть діяти за конкурентним механізмом, приєднуючись до активного центру ферменту і перешкоджаючи тим самим перетворенню субстрата. Неконкурентна активація зустрічається часто, оскільки такі активатори не впливають на утворення фермент-субстратного комплекса i прискорюють перетворення субстрата в продукт. Для встановлення каталітичних характеристик активаторів вивчали експериментально кінетику приросту хлорофілсинтезуючих мікроводоростей за різних значень концентрацій активаторів [8].

Експериментальна частина. Для дослідження впливу активування на процес поглинання вуглекислого газу використовували мікроводорості - Chlorella vulgaris. Ї̈ї культивували протягом 11 діб у шести фотобіореакторах об'ємом 1 дм³ $^{3}$ Живильні речовини - вуглекислий газ та елементи мінерального живлення клітини мікроводорості отримують безпосередньо з навколишнього рідкого середовища, засвоюючи їх всією своєю

Наукові праці, Том 83, випуск 1 Scientific Works, Volume 83, Issue 1 
поверхнею. На час проведення даного дослідження температуру підтримували в межах $\mathrm{t}=30^{\circ} \mathrm{C}$, для досягнення максимально сприятливих умов культивування. Так, як оксиди $\mathrm{N}_{\mathrm{x}} \mathrm{O}_{\mathrm{y}}$, i $\mathrm{P}_{2} \mathrm{O}_{5}$ у водному середовищі утворюють відповідні аніони $\mathrm{NO}_{9}^{-} ; \mathrm{H}_{2} \mathrm{PO}_{4}^{-}$, та засвоюється мікроводоростями у вигляді цих же аніонів, тому їх вплив на поглинання вуглекислого газу, а від так на приріст хлорофілсинтезуючих мікроводоростей вивчали за різних їх значень концентрацій.

Для дослідження впливу оксидів нітрогену на приріст хлорофілсинтезуючих мікроводоростей у першому фотобіореакторі концентрація аніону $\mathrm{NO}_{3}^{-}$становила $8,5 \mathrm{Mr} / \mathrm{m}^{3}$, у другому $-15,6 \mathrm{~m} / \mathrm{m}^{3}$, у третьому -34 $\mathrm{Mг} / \mathrm{M}^{3}$, а у четвертьому- $68 \mathrm{мг} / \mathrm{M}^{3}$. Для дослідження впливу оксиду фосфору $\left(\mathrm{P}_{2} \mathrm{O}_{5}\right)$ на приріст хлорофілсинтезуючих мікроводоростей у першому фотобіореакторі концентрація аніону аніону $\mathrm{H}_{2} \mathrm{PO}_{4}^{-}$становила 0,02

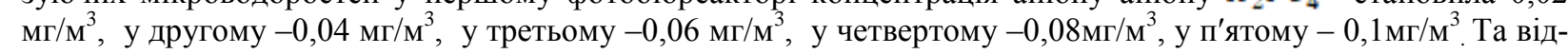
повідно контрольний розчин, який не містив відповідних аніонів у двох варіантах досліджень.

Приріст біомаси хлорофілсинтезуючих мікроводоростей, за таких умов визначали фотоколориметричним методом 3 використанням синього світлофільтра згідно закону Бугера-Ламберта-Бера.[9] Оскільки оптичне поглинання світла за даної довжини хвилі пропорційне концентрації мікроводоростей, одержані експериментальні дані накопичення біомаси мікроводоростей в залежності від часу в межах досліджуваної концентрації $\mathrm{NO}_{9}^{-}$) та $\mathrm{H}_{2} \mathrm{PO}_{4}^{-}$пропорційні значенням оптичних густин. Вимір оптичної густини досліджуваних і контрольних розчинів виконували відносно розчину порівняння. У нашому випадку розчином порівняння була вода.

В процесі обробки експериментальних даних було отримано графічні залежності, що показують зміну концентрації мікроводоростей в часі за різних значень концентрацій $\mathrm{NO}_{g}^{-}$(рис.1) та $\mathrm{H}_{2} \mathrm{PO}_{4}^{-}$(рис. 2) відповідно в середовищі культивування при одноразовому введенні.

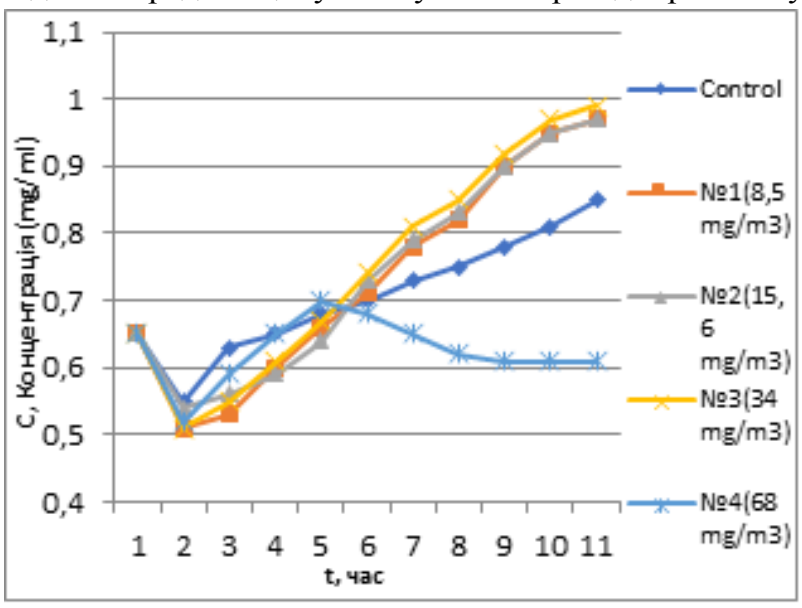

Рис. 1. - Залежність зміни концентрації клітин мікроводоростей в часі за відповідних концентрацій $\mathrm{NO}_{3}^{-}$

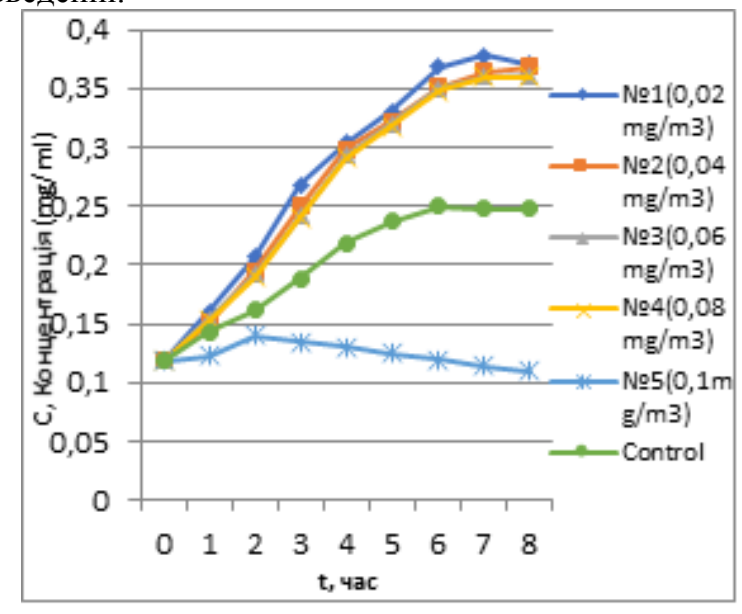

Рис. 2. - Залежність зміни концентрації клітин мікроводоростей в часі при відповідних концентраціях $\mathrm{H}_{2} \mathrm{PO}_{4}^{-}$

Із зростанням концентрації $\mathrm{NO}_{3}^{-}$та $\mathrm{H}_{2} \mathrm{PO}_{4}^{-}$збільшується приріст клітин мікроводоростей в порівнянні 3 контролем. Як видно на (рис. 1) 4 проба на другий день поводить себе так само як інші, тобто має місце фаза пристосовання до двох діб, з третьої доби починається незначний ріст, який на 5-ту добу є вищий ніж у контрольній пробі, проте з шостої доби спостерігається спад і наступні п'ять діб спостерігається зменшення приросту. При вищих значення концентрацій $\mathrm{NO}_{\text {g }}^{-}$має місце відмирання мікроводоростей в порівнянні 3 контролем.

Аналізуючи дані (рис. 2.) слід зазначити, що із зростанням концентрації $\mathrm{H}_{2} \mathrm{PO}_{4}^{-}$збільшується приріст клітин мікроводоростей, але до певного значення. Як видно на (рис.2) 5 проба на перший та другий день поводить себе так само як інші, тобто зростає, з третього дня починається спад, який продовжується решту днів експериментального дослідження. Водночас спостерігається збільшення маси клітин мікроводоростей в контрольній ємності, яка не зазнала впливу аніону $\mathrm{H}_{2} \mathrm{PO}_{4}^{-}$. Це говорить про те що ми додали згубну дозу $\mathrm{H}_{2} \mathrm{PO}_{4}^{-}$для приросту хлорофілсинтезуючих мікроводоростей типу Chlorella.

Підводячи підсумок отриманим результатам можемо припускати, що продукти спалювання палива - оксиди нітрогену $\left(\mathrm{N}_{\mathrm{x}} \mathrm{O}_{\mathrm{y}}\right)$, оксид фосфору $\left(\mathrm{P}_{2} \mathrm{O}_{5}\right)$, до певних значень концентрацій виступають активаторими поглинання вуглекислого газу хлорофілсинтезуючими мікроводоростями.

Визначальним параметром, який характеризує приріст мікроводоростей може бути $\delta_{\mu}-$ це питома швидкість приросту або коефіцієнт питомого приросту $\left(\mathrm{c}^{-1}\right)$ : 


$$
\delta_{k}=\delta C_{1} / C \times \delta t
$$

де $\delta C_{1}-$ приріст мікроводостей ; $C$ - концентрація мікроводоростей,

3 іншого боку коефіцієнт приросту також може бути визначений за рівняння:

$$
\delta C / \delta t=\mu \times C
$$

Згідно рівняння, коефіцієнт приросту характеризує відносний приріст концентрації мікроводоростей за одиницю часу. Якщо протягом певного часу $\delta \mu$ залишається незмінним, то такий приріст називається експоненційним, а відповідний йому проміжок часу - експоненційною фазою приросту.

Проінтегрувавши рівняння (3), знаходимо постійну інтегрування за умови, що в початковий момент часу $\mathrm{t}=0$ наявна вихідна концентрація клітин мікроводоростей $C_{0}$.

$$
C=C_{0} \times \exp (\mu t)
$$

Оскільки логарифмічна залежність концентрації клітин мікроводоростей від часу в період експоненційного приросту є лінійною залежністю то це дає можливість визначити коефіцієнт приросту $\mu$ як тангенс кута нахилу експериментальних прямих. Тому підставивши експериментальні дані у рівняння (4) утримаємо залежністі $\operatorname{Ln} C=\mathrm{f}(t)$, які зображені на рис. 3 ; рис.4.

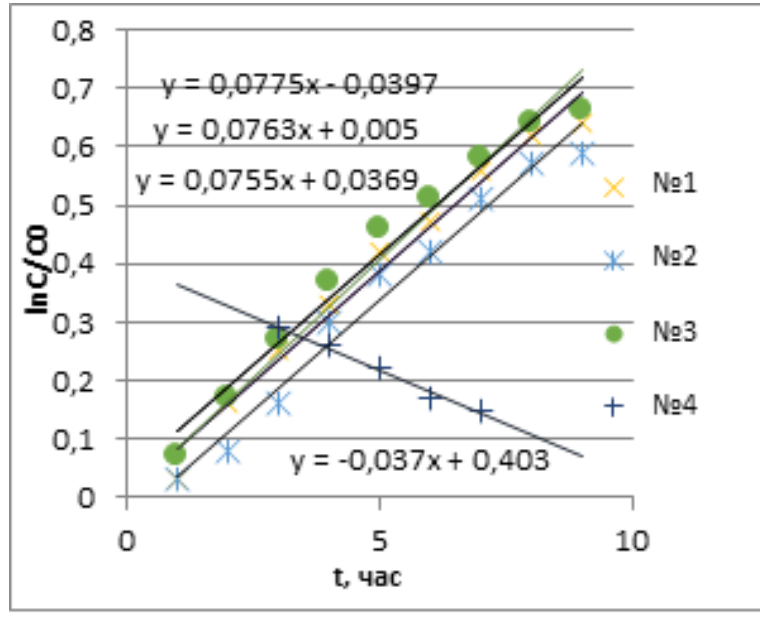

Рис. 3. - Залежність зміни логарифму концентрації суспензії клітин мікроводоростей від часу (за відповідних концентрацій $\mathrm{NO}_{3}^{-}$)

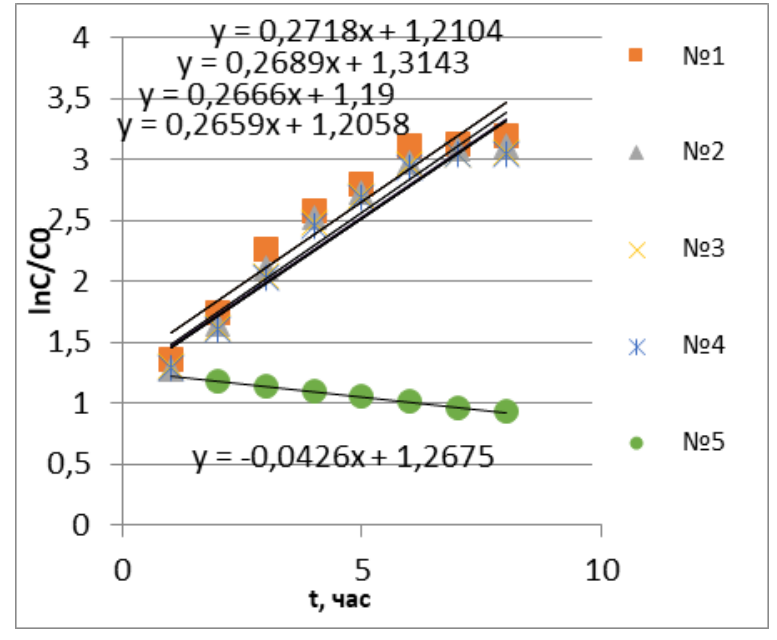

Рис. 4. - Залежність зміни логарифму концентрації суспензії клітин мікроводоростей від часу (за відповідних концентрацій $\mathrm{H}_{2} \mathrm{PO}_{4}^{-}$)

Користуючись прямими одержаними з графіків визначаємо коефіцієнт приросту $\mu$. Отримані залежності дозволяють визначити коефіцієнт приросту $\mu$, як тангенс кута нахилу експериментальних прямих.

Оскільки в контрольних ємкостях є збільшення приросту біомаси мікроводоростей, то значення коефіцієнта приросту додатне, $\mu=0,036 \mathrm{c}^{-1}$ (рис. 3), $\mu=0,1394 \mathrm{c}^{-1}$ (рис. 4).

Для аніону $\mathrm{NO}_{2}^{-}$за концентрації $8,5 \mathrm{Mr} / \mathrm{M} 3-0,076 \mathrm{c}^{-1}$; за концентрації $15,6 \mathrm{мг} / \mathrm{M}^{3}-0,077 \mathrm{c}^{-1}$; за концен-

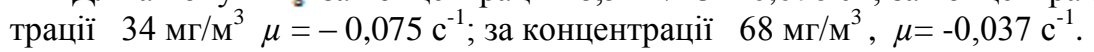

Оскільки в 1-4 пробах є збільшення приросту біомаси мікроводоростей, тому значення коефіцієнта приросту є додатнім. У випадку п'ятої проби має місце зменшення приросту мікроводоростей, тому значення коефіцієнта приросту $\mu$ є від'ємне.

Для аніону $\mathrm{H}_{2} \mathrm{PO}_{4}^{-}$за концентрації $0,02 \mathrm{мг} / \mathrm{M}^{3}, \mu=0,2666 \mathrm{c}^{-1}$; за концентрації $0,04 \mathrm{мг} / \mathrm{M}^{3}, \mu=0,2718 \mathrm{c}^{-1}$; за концентрації $0,06 \mathrm{мг} / \mathrm{M}^{3}, \mu=0,2689 \mathrm{c}^{-1}$; за концентрації $0,08 \mathrm{мг} / \mathrm{M}^{3}, \mu=0,2659 \mathrm{c}^{-1}$; за концентрації $0,1 \mathrm{мг} / \mathrm{M}^{3}$, $\mu=-0,0426 \mathrm{c}^{-1}$.

Оскільки в 1-4 пробах є збільшення приросту біомаси мікроводоростей, то значення коефіцієнта приросту - додатнє. У випадку п'ятої проби, коли концентрація $\mathrm{H}_{2} \mathrm{PO}_{4}^{-} \mu=-0,1 \mathrm{мг} / \mathrm{M}^{3}$ має місце зменшення приросту біомаси мікроводоростей, тому значення коефіцієнта приросту $\mu$ - від’ємне.

Математична модель приросту біомаси мікроводоростей в залежності від концентрації активаторів за результатами експериментальних досліджень може бути описана наступним чином: 


$$
\left\{\begin{array}{l}
\frac{d C}{d x}=\mu_{1} C \\
\frac{d C}{d x}=\mu_{1} C-\mu_{2} C \\
x=0, C=C_{0} x
\end{array}\right.
$$

де, $x$ - концентрація $\left(\mathrm{NO}_{9}^{-}\right),\left(\mathrm{H}_{2} \mathrm{PO}_{4}^{-}\right) ; C$ - концентрація мікроводоростей у суспензії; $\mu_{1}, \mu_{2}$ коефіцієнти приросту за позитивного та негативного значення при заданні відповідних початкових умов .

Перше рівняння системи описує приріст концентрації мікроводоростей в залежності від концентрації аніону $\mathrm{NO}_{2}^{-}$або $\mathrm{H}_{2} \mathrm{PO}_{4}^{-}$.

При досягненні певного, критичного значення концентрації аніону за результатами експериментальних досліджень спостерігається негативний приріст біомаси мікроводоростей.

Це явище супроводжується відповідним значенням коефіцієнту приросту - $\mu_{2}$.

Для вирішення лінійної системи (4) застосовано операційний метод Ейлера. Рішення даної моделі має вигляд;

$$
C=C_{0} \frac{\mu_{1}}{\left[\mu_{2}+\mu_{1}\right)}\left[e^{\mu_{1} x}-e^{-\mu_{2} x}\right]
$$

Рівняння (5) описує зміну концентрації біомаси мікроводоростей в межах концентрацій аніонів від 0 до безмежності.

Дане рівняння дозволяє розраховувати концентрацію аніонів, за якої досягається максимальне значення концентрації біомаси мікроводоростей, щ адекватно максимальному поглинанню вуглекислого газу.

Для цього необхідно знайти умову екстремуму, а саме диференціюючи його та прирівнюючи результат до нуля;

$$
\frac{d C}{d x}=0
$$

Після проведення незначних математичних перетворень приходимо до рішення (7) за яким знаходимо концентрацію аніонів для досягається максимального значення концентрації біомаси мікроводоростей при відомому значенні коефіцієнтів приросту - $\mu$;

$$
x_{\max }=\frac{\ln \mu_{2}-\ln \mu_{1}}{\left(\mu_{1}+\mu_{2}\right)} ;
$$

Використовуючи дані математичної обробки результатів експериментальних досліджень приросту біомаси мікроводоростей ми знайшли коефіцієнти приросту $\mu_{1}$ та $\mu_{2}$.

Після підстановки отриманих значень у розв язок математичної моделі рівняння (7) розраховуємо оптимальне значення концентрацій $\mathrm{NO}_{\mathrm{g}}^{-}$для приросту мікроводоростей типу Chlorella.

$$
x_{\max }=\frac{\ln \mu_{2}-\ln \mu_{1}}{\left(\mu_{1}+\mu_{2}\right)}=\frac{\ln (-0,037-\ln 0,076)}{(0,076-0,037)}=18,46 \text { мг } / \mathcal{M}^{3} ;
$$

Аналогічно підставляємо значення у рівняння (7) та розраховуємо оптимальне значення концентрації $\mathrm{H}_{2} \mathrm{PO}_{4}^{-}$для приросту мікроводоростей Chlorella.

Для перевірки адекватності математичної моделі будували аналогічні графіки залежності концентрації оксидів ( $\mathrm{NO}_{2}^{-} ; \mathrm{H}_{2} \mathrm{PO}_{4}^{-}$,) від коефіцієнтів приросту $\mu$ отримані експериментальними методом (рис.5 та рис.6). 


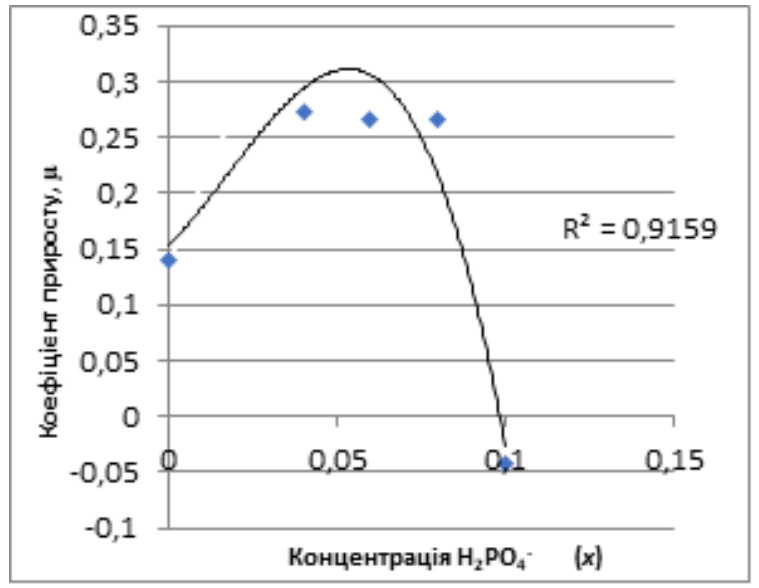

Рис. 5. - Залежність коефіціснту приросту мікроводоростей $\mu$. від концентрації $\mathrm{H}_{2} \mathrm{PO}_{4}^{-}$

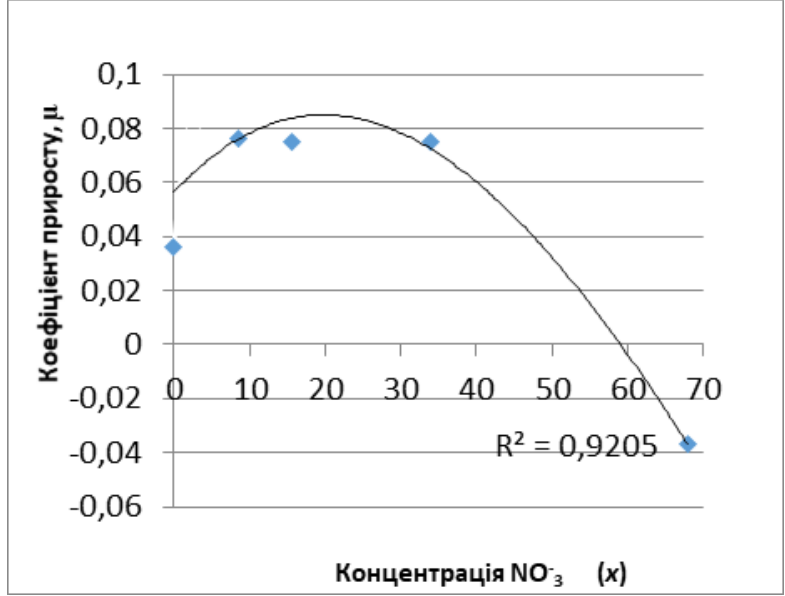

Рис. 6. - Залежність коефіціснту приросту мікроводоростей $\mu$. від концентрації $N O_{a}^{-}$

3 ( рис. 5.) видно, що максимальний приріст концентрації мікроводоростей досягається за концентрації $\mathrm{H}_{2} \mathrm{PO}_{4}^{-} \approx 0,06 \mathrm{мг} / \mathrm{M}^{3}$. Також 3 ( рис. 6.) видно що максимальний приріст концентрації мікроводоростей досягається за концентрації $N O_{a}^{-} \approx 18 \mathrm{Mr} / \mathrm{M} 3$. Це свідчить про адекватність математичної моделі.

Отримані результати дозволяють в подальшому прогнозувати обладнання для здійснення технології поглинання вуглекислого газу за умови присутності $\mathrm{N}_{\mathrm{x}} \mathrm{O}_{\mathrm{y}}$ та $\mathrm{P}_{2} \mathrm{O}_{5}$.

Висновок. Проведені експериментальні дослідження поглинання вуглекислого газу хлорофілсинтезуючими мікроводоростями типу Chlorella за умов присутності активаторів $\mathrm{N}_{\mathrm{x}} \mathrm{O}_{\mathrm{y}}$ та $\mathrm{P}_{2} \mathrm{O}_{5}$. На основі отриманих результатів побудовано експериментальні криві приросту концентрації мікроводоростей від часу. Розроблено математичну модель приросту біомаси мікроводоростей в залежності від концентрації $\mathrm{NO}^{-3},\left(\mathrm{~N}_{\mathrm{x}} \mathrm{O}_{\mathrm{y}}\right)$

та $\mathrm{H}_{2} \mathrm{PO}_{4}^{-},\left(\mathrm{P}_{2} \mathrm{O}_{5}\right)$. Встановлено розрахункове значення оптимальної концентрації $\mathrm{NO}_{3}^{-}$та $\mathrm{H}_{2} \mathrm{PO}_{4}^{-}$для приросту мікровдоростей типу Chlorella та підтверджено іiі експерментальним методом.

\section{References}

1. TSN.ua. (2017) Hlobalne poteplinnia. Yak Zemlia zminiuie svoie oblychchia. Spetsproekt TSN.ua. Retrieved from: https://tsn.ua/special-projects/warming. vid 25 bereznia.

2. Dyachok, V. V., Huhlych S. I., Levko O.B. (2015). Vyvchennia vplyvu temperatury na kinetyku poglynannya vuglekyslogo gazu mikrovodorostyamy, 812, 365-372.

3. Zolotar`ova, O.K., Shnyukova Ye.I., Syvash O.O., Myxajlenko N.F. (2008). Perspektyvy vykorystannya mikrovodorostej u biotexnologiyi. K.: Al terpres. 234.

4. Diachok, V. V., Huhlych S.I., Katysheva V.V., Mandryk S.T. (2017) Pohlynannia vuhlekysloho hazu iz sumishi povitria z dioksydom sirky . Naukovi pratsi. 81,1, 59-65.

5. Poltorak, O.M.,ChukhraiO.S. (1972). Fyzyko-khymycheskye osnovy fermentatyvnoho katalyza / Red. M.M. Poplavskaia. M.:Vysshaia shkola.,.311.

6. Dyachok, V., Ilkiv I. (2013) The mechanism of extraction from solid bodies cellular structure, 7,1, 23-27.

7. Dyachok, V., Huhlych, S., Yatchyshyn, Y., Zaporochets, Y., Katysheva, V. (2017) About the problem of biological processes complicated by mass transfer. 11,1, 111-116.

8. Manakov, M. N. Pobedymskyi D.H. (1990) Teoretycheskye osnovy tekhnolohyy mykrobyolohycheskykh proyzvodstv. M.: Ahropromyzdat,. 272.

9. Stepan, D. J. Shockey, R. E., Moe, T. A., Dorn, R. 1. (2002) 2.3 carbon dioxide sequestration using microalgae systems, 1, 1-27.

Отримано в редакцію 16.04.2019

Прийнято до друку 20.06.2018
Received 16.04.2019

Approved 20.06.2018 